\title{
Study on Chinese Listed Companies Financial Early Warning System Yumei Ding
}

\author{
School of management, Wuhan University of technology, Wuhan, 430070, China
}

Keywords: Listed companies, financial crisis, financial early warning system.

\begin{abstract}
With the development of the socialist market economy, China's listed companies become more and more, the core issue of the development of the company is financial problems. While fastgrowing companies, corporate finance will face a variety of challenges. In order to ensure the healthy development of corporate finance, not only do the basic financial management, but also to do early warning measures, and make the financial crisis in reasonable control science. The purpose of the control of financial crisis is to make the amount charged of the controlled object close to the set point. At present, there are many problems about convergence on enterprise financial crisis results and management, which severely restricted the application and promotion of financial crisis early warning technology. Therefore, this paper presents an IT platform for financial early warning system based on K-Means algorithm tool.
\end{abstract}

\section{Introduction}

With China's socialist market economy continues to develop and the overall development of the globalization of trade, the role of business management in the enterprise development is even more important, and financial management is the top priority of all business management. Financial crisis is the most prominent problem of the financial management .How to prevent the financial crisis, and let the corporate finance have a healthy development has become a key issue. Development of network technology offers the potential for business groups to build a sound financial early warning system.

Therefore, we use modern information network technology and software engineering techniques to design a financial early warning system for corporate finance based on IT platform.

\section{Algorithms and Modelling}

The discussed model is given as follow: In order to ensure accuracy of the results, we proposed clustering algorithm, this paper, K-Means clustering method to generate classification evaluation of a specific set of financial indicators'-means algorithm is a more typical by-point modified iterative dynamic clustering algorithm. Algorithm program as shown below:

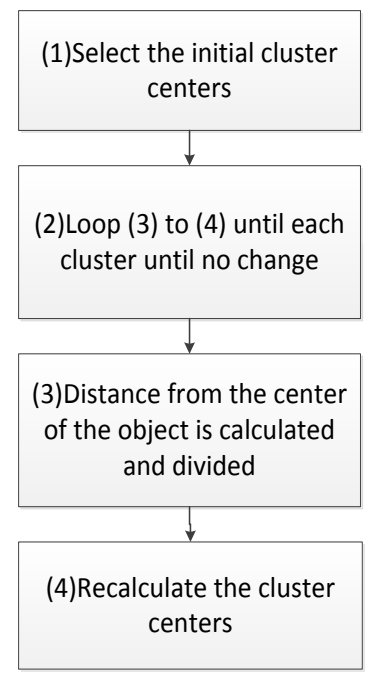

Fig. 1: K-means Implementation Process 
After algorithm determined, we choose early warning model. Compared to the decision tree, the accuracy is not high. We use the neural network model to build early warning model, from the system point of view, the artificial neural networks are composed of a simple nonlinear cell or connection point through the extremely rich and perfect connection and adaptive nonlinear dynamic system. Each neuron of the neural network is a small processing cell. It accepts input signal from the input connection to produce activated value passing to the output connections. Because there is a different way of connection between neurons, neural network model in the form of different structure has been formed. On the structure, the neural network can be divided into input layer and output layer and hidden layer. Below is a three-layer network diagram.

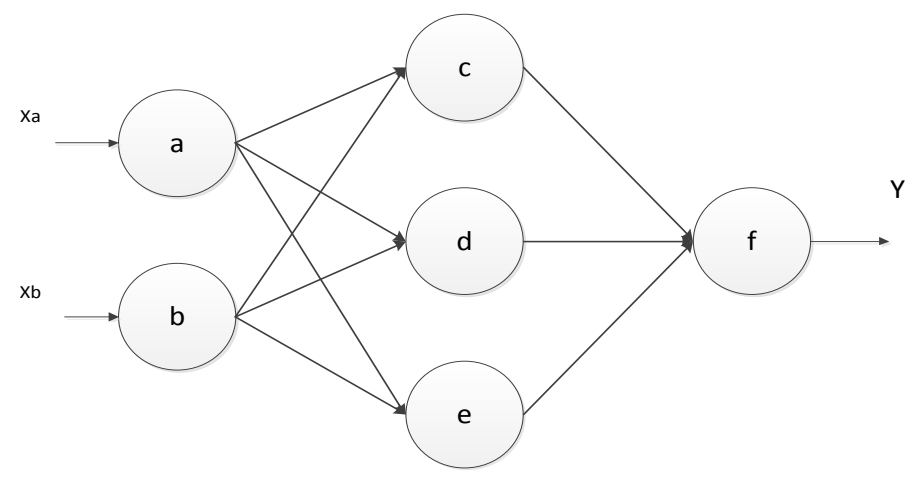

Fig.2: Basic structure of neural network model

After determined the basic model and algorithm, it is about to build financial early warning system model, the steps to build financial early warning model are similar with common model building. The main process is shown in the figure below:

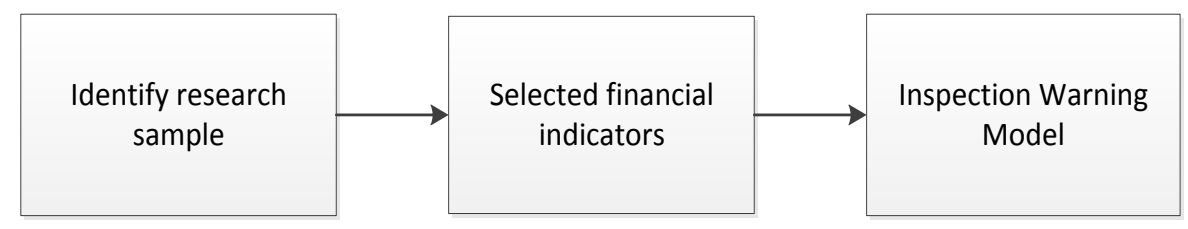

Fig.3: Financial early warning model build process

Scholars at home and abroad use the neural network method to establish some financial crisis warning model. The principles of these models are basically the same, all is putting the financial index as input variables of the model, through neural network training, concluding that the future financial situation: "excellent, worse", the two value judgments. This research adopts the Clementine10.0 neural network modeling tool, its output is "fail, warning, safe" three states.

\section{Financial Early Warning Indicator System}

Modern financial management theory that measure a company's financial condition, depending on solvency, asset management, profitability, cash flow and ability to grow the capacity of the enterprise business.

\section{Indicator System}

Designed without taking into account national, regional and industry characteristics. In the use of these early warning indicators of financial analysis, if not binding region, industry characteristics, the analysis is incomplete. We should also take into account: the company's financial information is complex, and it cannot be reflected only by a few simple financial indicators of the financial condition and operating results. 


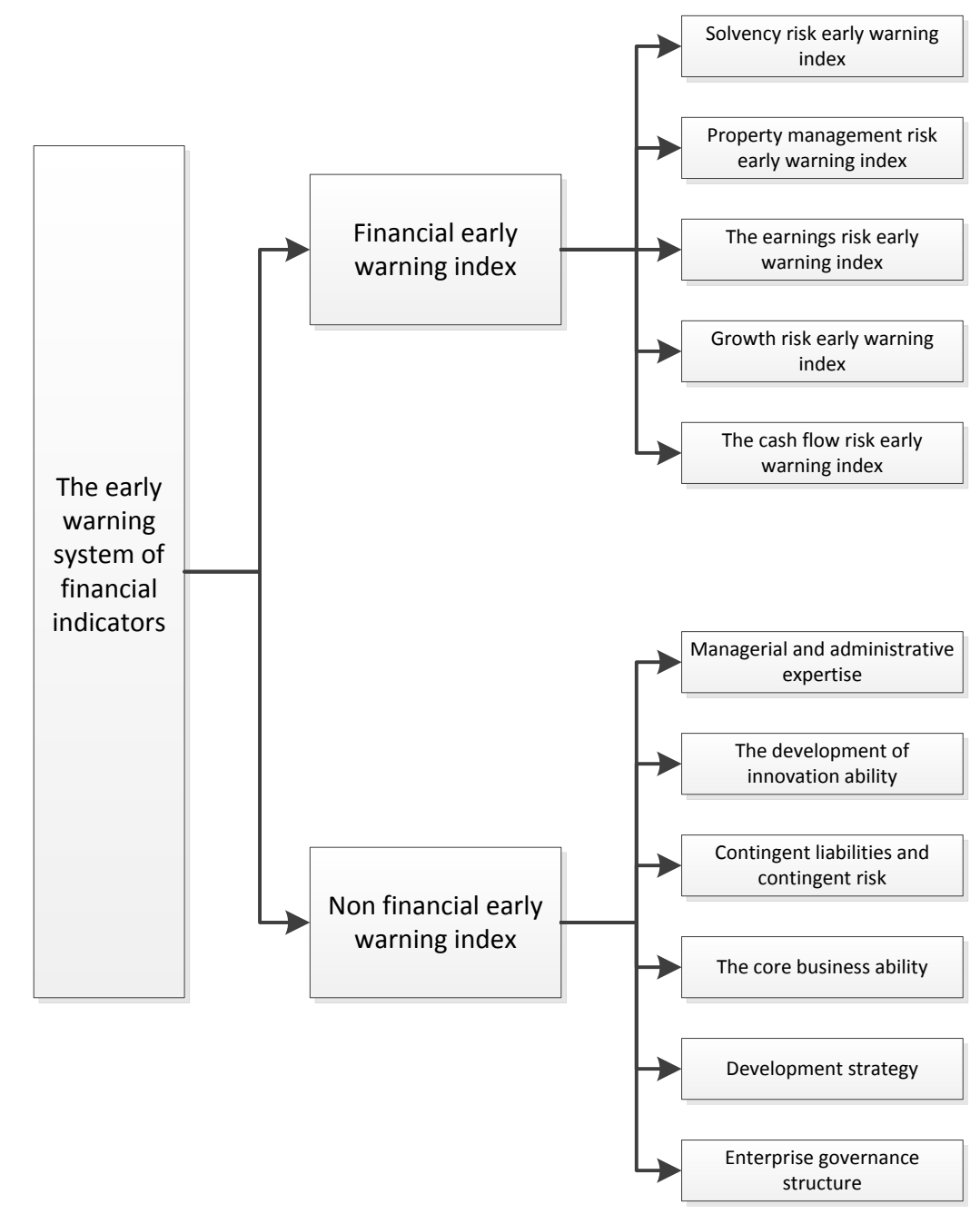

\section{Warning criteria}

Fig.4: Financial Early Warning Indicator System

Design guidelines for many forms of early warning, early warning indicators of the main factors that warning, integrated warning. This article focuses on early warning indicators.

Refers to the issue of early warning indicators of different levels of alerts based on changes in the value of early warning indicators of size. And if you want to make an alarm indicator for $\mathrm{X}$ and if the gray area is for $(\mathrm{Xa}, \mathrm{Xb})$, safe area for $\mathrm{X}>\mathrm{Xb}$, primary danger zone $(\mathrm{Xc}, \mathrm{Xa})$, medium risk area $(\mathrm{Xd}, \mathrm{Xc})$, and the higher the danger zone for $\mathrm{X}<\mathrm{Xd}$, the basic criteria for alerts can be shown as bellow:

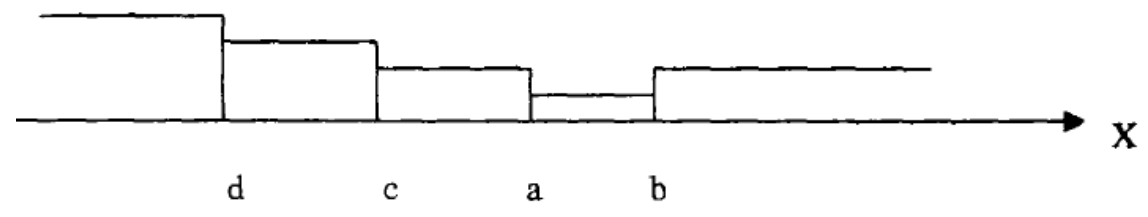

Fig.5: Basic criteria for alerts

When $\mathrm{X}>\mathrm{Xb}$, no alarm;

When $\mathrm{Xa}<\mathrm{X}<\mathrm{Xb}$, accountable experience, a comprehensive analysis to determine whether the alarm;

When $\mathrm{Xc}<\mathrm{X}<=\mathrm{Xa}$, the issue of an alert:

When $\mathrm{Xd}<\mathrm{X}<=\mathrm{Xc}$, issued two alerts;

When $\mathrm{X}<=\mathrm{Xd}$, issued three alarms. 


\section{The construction of financial early warning system based on IT platform}

Building the financial early warning system based on IT platform of process is similar with most of the system software design process based on IT platform, mainly including the demand analysis, module design, system implementation and system test. Let's analyze module design and the overall design of the system in detail.

Enterprise financial risk early warning system, the essence of which is based on the enterprise management situation and the reason of fluctuation characteristic, through the enterprise financial conditions, financial results and operating performance of comprehensive analysis, in order to obtain business fluctuations that may occur, and even the turmoil of the information, and advanced early warning system. Therefore, the comprehensive analysis to the enterprise management is the foundation of the enterprise financial risk early warning. The composition of enterprise financial warning system is showed in the figure below:

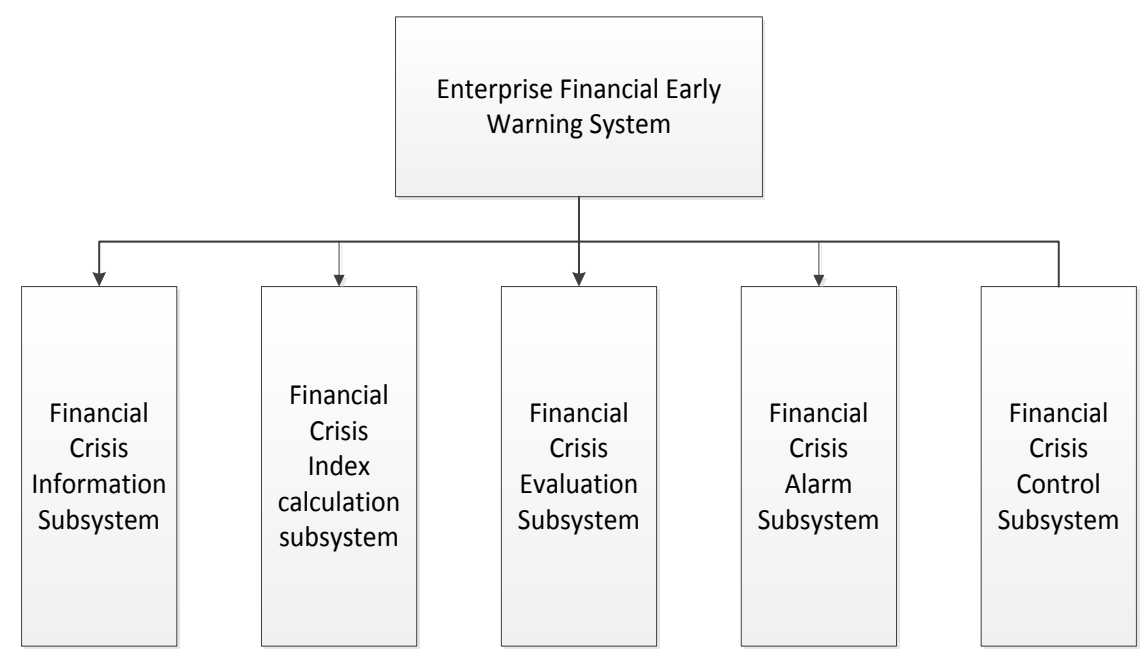

Fig.6 The structure of the financial early warning system

Information acquisition subsystem's main function is collecting enterprise business operation of financial or non-financial information from each department. When deciding the scope and content of information acquisition, we should also pay attention to the risks of the early signal.

Index calculation subsystem is using the information provided by the financial crisis information subsystem, according to the established evaluation index system of financial crisis evaluation index formula, to calculate the specific parameter values, for the use of comprehensive evaluation and financial crisis early-warning subsystem, which mainly including data acquisition, library, financial input three modules indicators.

Comprehensive evaluation subsystem is using the calculation result of financial crisis evaluation subsystem, carrying on the comprehensive evaluation, to obtained comprehensive evaluation value. It includes functional modules are as follows:

Model database, used to store a variety of data needed for the financial early warning model, preparing for setting up rule base and early warning model; Function block for factor regression analysis algorithm, used in regression analysis on the index; K-Means algorithm, used for clustering analysis for the output financial index of regression analysis, an algorithm program is classified into five types, and according to the average sort, to save results to the rule set in the rule base; Neural network algorithm, used to output $\mathrm{K}$ - Means clustering neural network model for the evaluation value building, the algorithm program output warning update module to save results to the knowledge base; Knowledge base updating program, used to hold and updated from the previous algorithm program calculation rules and the early warning result; Early warning module, used to view the enterprise current data according to business rules, and invoke the model algorithm, to calculate the financial position of an enterprise, and output the results to the alarm program; Financial alarm subsystem, using comprehensive evaluation subsystem information, according to the calculated reflects the crisis of enterprise financial crisis index, comprehensive evaluation and early warning value, according to the different levels of warnings to a certain alarm mode. 
In addition, the financial crisis early warning should pay attention to the accuracy of the early warning, at the same time, more should be concerned about the availability of users. The current enterprise's result of financial crisis warning and the organic connection and management program has great defects, so we also design the financial control subsystem.

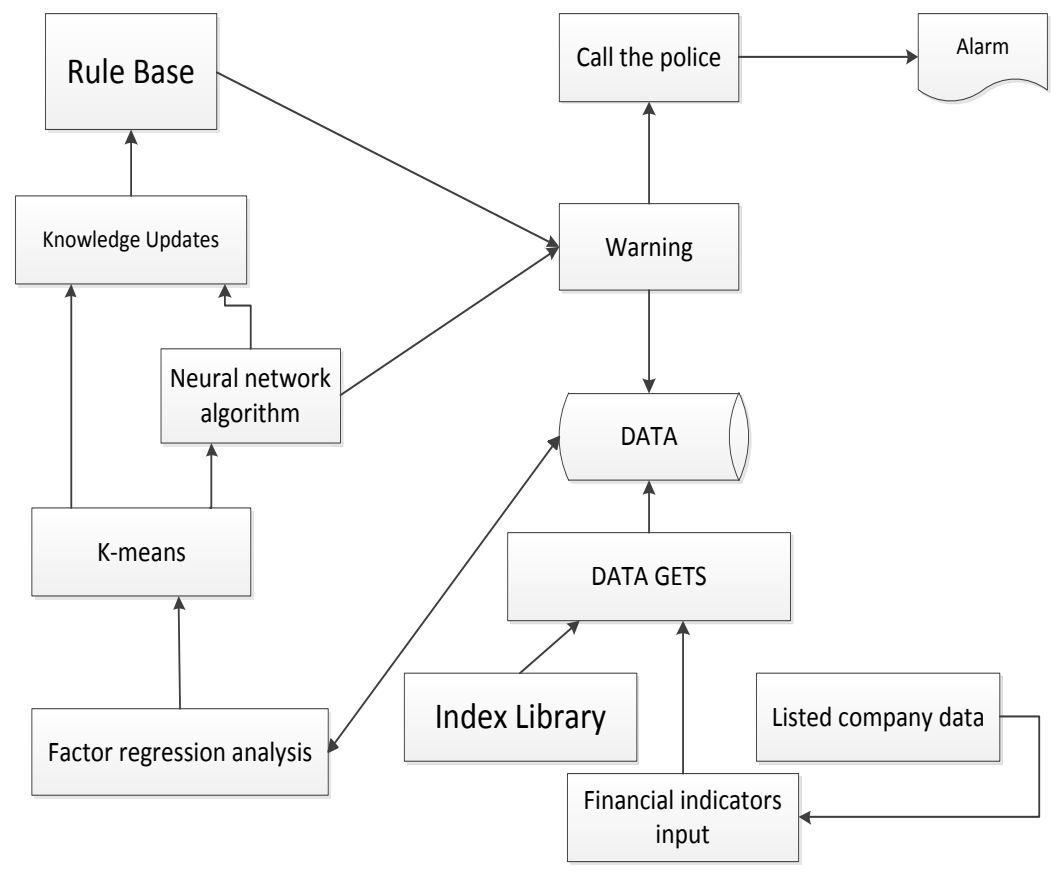

Fig.7 System Diagram

As shown, the basic idea is first gathering of all kinds of listed companies on the market of the existing financial, information to obtain the relevant data of the financial early warning system, and save the data to the database after finishing; The regression analysis algorithm using financial index of enterprises data, to calculate warning value, then calling K-Means algorithm to classify the enterprise, building the classification library of enterprise financial characteristics; Calling the neural network to build the financial early warning model based on discrete values input, and save the generated model to rule base; Establishing basic rule base for enterprise early warning.

\section{Summary}

In this paper, the financial crisis, combined with the social background of the moment, in the Internet environment, information technology, IT-based platform designed financial early warning system, the core algorithm of the system is K-means and model is a neural network model, using the classic B / S architecture. Using this system, the listed company's suppliers can develop appropriate credit policies and collection policies to ensure timely recovery of accounts receivable, reduce bad debt losses by information provided by financial early warning system.

\section{References}

[1] Chang-jiang sun, Sun Yin. Based on financial early warning system of corporate governance factors analysis [J]. Journal of academic exchanges, 2014, (5):121-124.

[2] Zhao Wei. Application of forestry enterprise financial early warning system [J]. Journal of China commerce and trade, 2014, (10):87-88.

[3] Zhang Xueliang. Based on the sustainable growth of hospital financial early warning system for building and application [J]. Chinese health economy, 2013, (11):85-87.DOI:10.7664 /CHE20131130.

[4] Hui-jun zhang. Establish and implement the financial early warning system of listed companies in China think [J]. Journal of economist, 2014, (6):134-134. 
[5] The cause of the financial risks in colleges and universities and the construction of financial early warning system [J]. Journal of Anhui technical college of electronic information, 2014, (2): 99-101,104.

[6] Zhao Bin. Discuss how to establish enterprise financial warning system [J]. Journal of cash flow for investment and cooperation, 2014, (3):129-129.

[7] Zhao Wei. Establishment and application of enterprise financial warning system [J]. Journal of academic exchanges, 2014, (4):128-131.

[8] Zhou Qian, vivid. The construction of private enterprises financial early warning system of our country analysis [J]. Journal of administrative assets and financial business, 2014, (9): 42-43. [10] Eman, O. E., Interactivebi-level multi-objective integer non-linear programming problem. Applied Mathematical Sciences, 5(65), 3221-3232, 2011. 